\title{
Development of Plastic Injection Mold using Simulation Technique Analysis Result
}

\author{
Mr. Pravin. P. Shinde ${ }^{1}$, Mr. Suresh. S. Patil ${ }^{2}$, Mr. Sandesh. S. Awati ${ }^{3}$, Mr. Rahul P Suryavanshi ${ }^{4}$ \\ Assistant Professor, Mechanical Engineering Department, P.V.P.I.T. Budhgaon ${ }^{1,3}$ \\ Associate Professor, Mechanical Engineering Department, P.V.P.I.T. Budhgaon ${ }^{2}$ \\ Assistant Professor, Mechanical Engineering Department, DACOE Karad ${ }^{4}$
}

\begin{abstract}
This paper deals with the development of Plastic Injection Mold using Simulation Technique results. In analytical solution Simulation and analysis is carried out with the help of mold flow software. In this work we use Autodesk mold flow software. From the simulation and analysis, the software for flow simulation provides sufficient information regarding filling time, injection pressure, defects like air traps, weld lines, sink mark, warpage etc. With these results, users can avoid the defect of the plastic in actual injection. The analysis will help the to design a mold with minimum modifications and which will also reduce the time and cost. The design will be validated by producing the component with the help of the designed mold.
\end{abstract}

Keywords: Simulation, Mold flow, Housing retainer, Mold Design.

\section{INTRODUCTION}

There are different ways of molding a plastic in to desired Name of Component: Housing Retainer shape. Injection molding is the most common and Molding type-Multi cavity injection mold important of all plastic processing processes. The process is extremely versatile, and can produce very complex shaped parts, with the use of multi-sided molds. The main concept of plastic molding is filling a molten state polymer into the mold cavity, allowed to solidify so that the polymer can take the required shape. To avoid the high costs and time delays problems associated with the start of manufacturing, it is necessary to consider the combined effects of part geometry, material selection, mold design and processing conditions. Using predictive analysis tools to simulate the injection molding process can evaluate and optimize interactions between these variables where the cost of change is minimal and the impact of the change is greatest.

\section{COMPONENT DETAIL:}

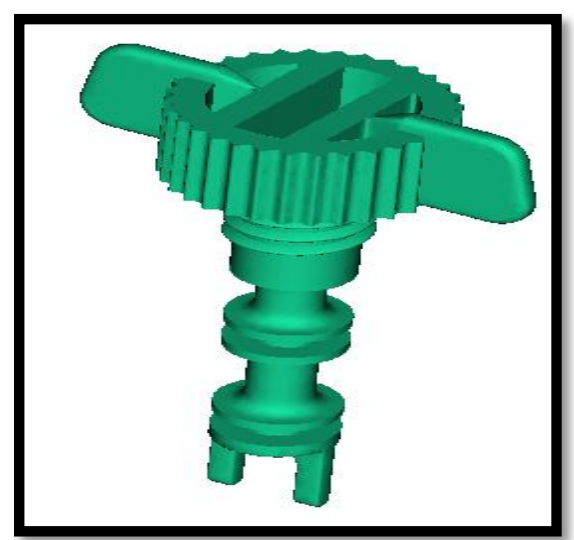

Fig 1 Housing Retainer
Material- Delrin 500P

This part is fixed at the bottom of the housing containing lubricating oil. Typically, the retainer has external treads that engages with the tapping in the Aluminum housing. The part is required to withstand the torque applied during fitment with the housing. Weld line, Warpage also needs to be controlled. The housing retainer is as shown in fig 1

\section{ANALYTICAL SOLUTION}

Analytical Solution involve 3D model and mold design created using CAD software such as CATIA. Meshing is carried out using pre-processor software. Analysis/ Simulation can be performed using suitable software in the CAE domain. Moldex or Mold flow are the common and popular software used in industry. For the work we use Autodesk mold flow software. Simulating the injection molding process reduces the need for costly physical prototypes, avoids potential manufacturing defects and helps deliver innovative products to market faster. Autodesk Simulation Mold flow helps to simulate the filling and packing phases of the plastic injection molding process, so we can better predict the flow behaviour of melted plastics and achieve higher-quality manufacturing.

\section{MOLD FLOW ANALYSIS RESULT}

\section{$\mathbf{1}^{\text {st }}$ Iteration}

Feeding system is designed with submarine gate having Cold Runner Melt Flow Channel diameter of $5 \mathrm{~mm}$, Gate diameter $1 \times 3 \mathrm{~mm}$. The simulation result of $1 \mathrm{st}$ iteration is as shown in fig 2 
IARJSET

International Advanced Research Journal in Science, Engineering and Technology

National Conference on Design, Manufacturing, Energy \& Thermal Engineering (NCDMETE-2017) AGTI's Dr. Daulatrao Aher College Engineering, Vidyanagar Extension, Karad

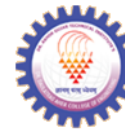

Vol. 4, Special Issue 1, January 2017

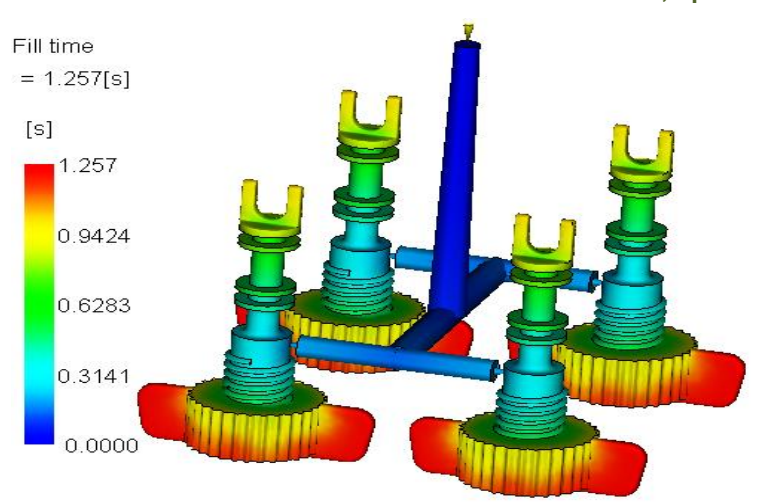

a) Fill time Analysis

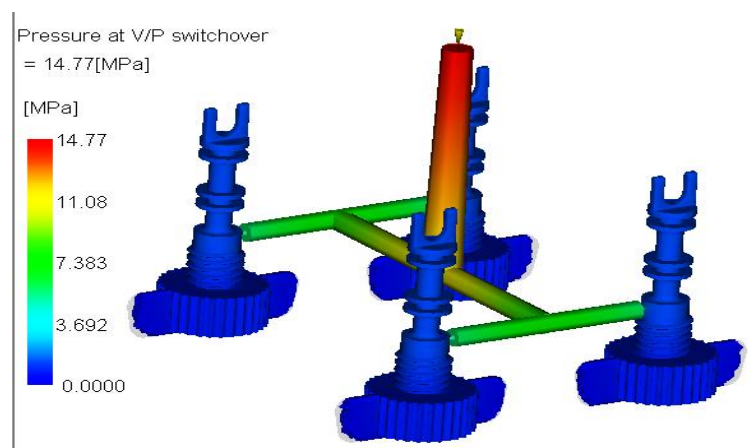

b) Injection Pressure

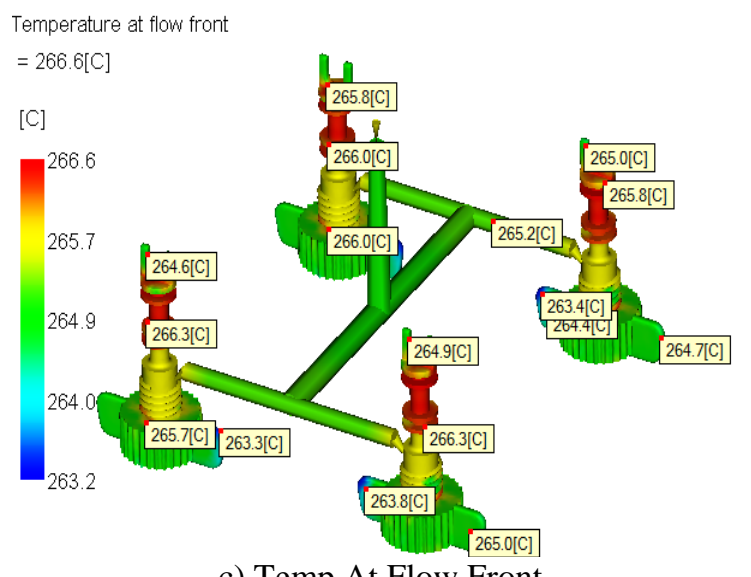

c) Temp At Flow Front

Sink marks estimate

Scale Factor $=1.000$

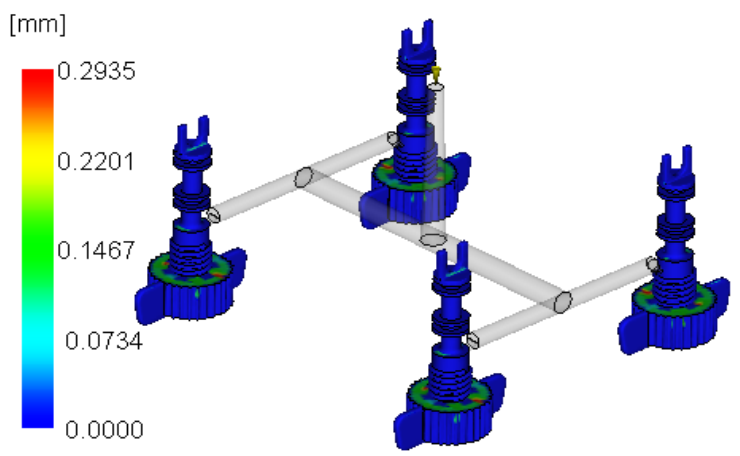

d) Sink Mark Analysis

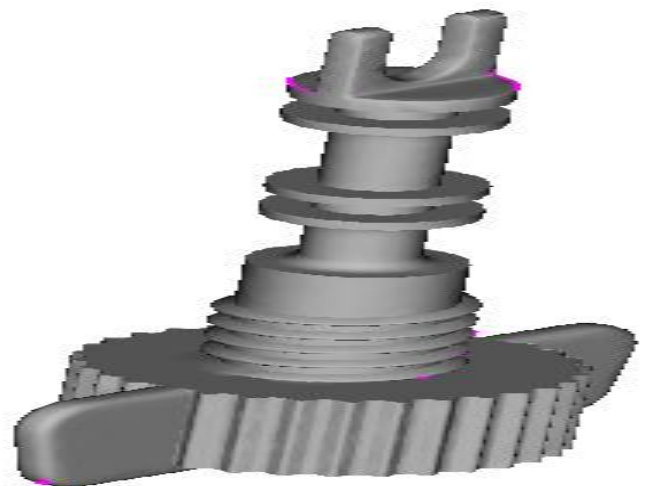

e) Weld line Analysis

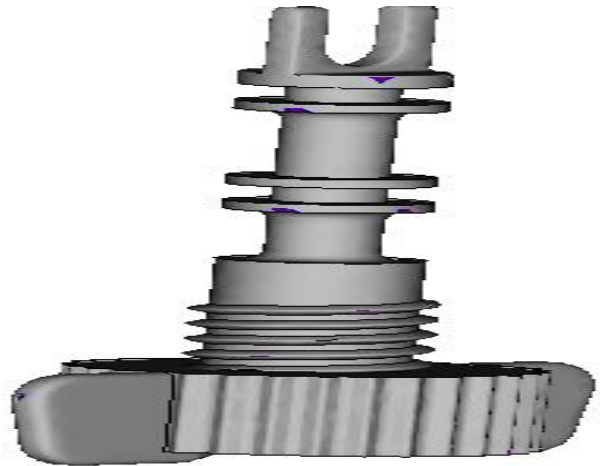

f) Air Traps Analysis

Deflection, all effects:Deflection Scale Factor $=2$.000
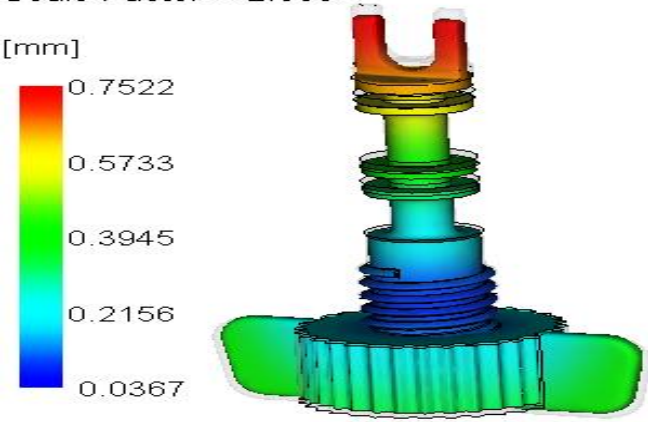

g) Warpage Analysis

Fig. 2: Analysis Result

Similarly two more analysis is carried out by changing some parameter. The result comparison of three iteration is as shown in table

Table No 1: Result Comparison

\begin{tabular}{|c|c|c|c|}
\hline & ${\text { Iteration } 1^{\text {st }}}^{\text {Iteration2 }}$ & Iteration $3^{\text {rd }}$ \\
\hline $\begin{array}{c}\text { Type of } \\
\text { gate }\end{array}$ & $\begin{array}{l}\text { Pin point } \\
\text { gate Dim } \\
: 1.2 \times 1.5 \mathrm{~mm}\end{array}$ & $\begin{array}{c}\text { Submarine } \\
\text { gate. Dim:1 } \\
\text { x } 3 \mathrm{~mm}\end{array}$ & $\begin{array}{c}\text { Submarine } \\
\text { gate. } \\
\text { Dim:1x3.5 } \\
\mathrm{mm}\end{array}$ \\
\hline Fill time & $1.257 \mathrm{Sec}$. & $1.226 \mathrm{Sec}$. & $1.226 \mathrm{Sec}$. \\
\hline $\begin{array}{l}\text { Injection } \\
\text { Pressure }\end{array}$ & $14.77 \mathrm{Mpa}$ & $18.41 \mathrm{Mpa}$ & $18.41 \mathrm{Mpa}$ \\
\hline
\end{tabular}


IARJSET

International Advanced Research Journal in Science, Engineering and Technology

National Conference on Design, Manufacturing, Energy \& Thermal Engineering (NCDMETE-2017)

AGTI's Dr. Daulatrao Aher College Engineering, Vidyanagar Extension, Karad

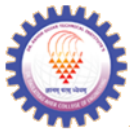

Vol. 4, Special Issue 1, January 2017

\begin{tabular}{|c|c|c|c|}
\hline $\begin{array}{c}\text { Temp. At } \\
\text { Flow } \\
\text { Front }\end{array}$ & $265{ }^{\circ} \mathrm{C}$ & $266.6{ }^{\circ} \mathrm{C}$ & $266.6{ }^{\circ} \mathrm{C}$ \\
\hline $\begin{array}{c}\text { Sink } \\
\text { Marks }\end{array}$ & $0.2540 \mathrm{~mm}$ & $0.2935 \mathrm{~mm}$ & $0.2935 \mathrm{~mm}$ \\
\hline Air Traps & Acceptable & Acceptable & Acceptable \\
\hline $\begin{array}{c}\text { Weld } \\
\text { Lines }\end{array}$ & Acceptable & Acceptable & Acceptable \\
\hline Warpage & $0.7143 \mathrm{~mm}$ & $0.7522 \mathrm{~mm}$ & $0.7525 \mathrm{~mm}$ \\
\hline
\end{tabular}

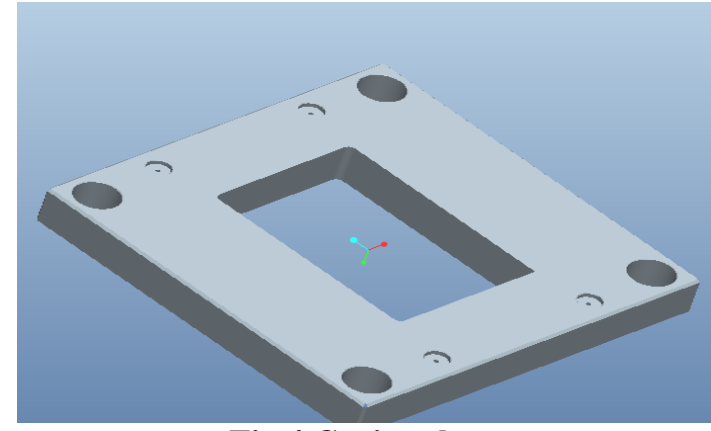

Fig 4 Cavity plate
Among all this iteration $1^{\text {st }}$ is the best iteration. Minimum defects are observed in this iteration also minimum sink mark and warpage observed in iteration three. by considering this iteration the part can be molded without defects and no hesitation with the provided feed system and process conditions. So iteration first is considered for mold design.

\section{VALIDATION}

The design is validated by producing the component with the help of the designed mold without affecting the component's functionality. Flow of plastic will be observed. Dimensional accuracy is checked with the specified dimensions. Visual and actual inspection will be done to find out the defects. Further, the component will be checked for fitment in the sub-assembly.

\section{MOLD DESIGN- 3D MODEL AND DRAWING}

\section{Core plate:}

A Core plate is a device used to mold a molding material into a certain shape. The section that is engaged in opening / closing movement is called a core plate as shown in fig 3

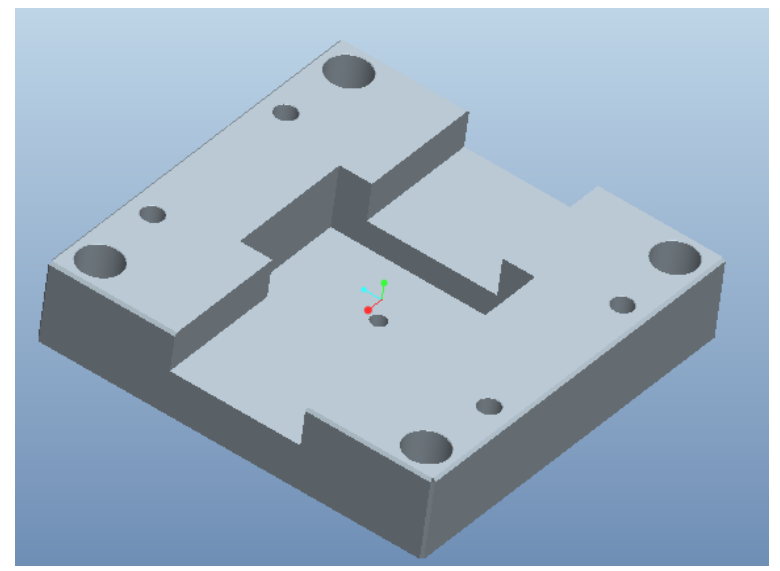

Fig 3 Core plate

\section{Cavity Plate:}

The cavity plate has a sprue bush, which is the entrance for molten plastic. The desired plastic product comes from the combination of the core and cavity plate.

\section{Core Back Plate:}

It prevents the core insert coming out and act as stiffener to core plate. Core Back Plate is as shown in fig 5

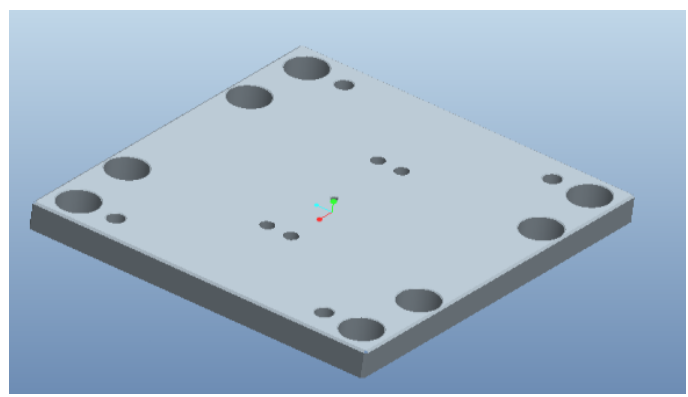

Fig 5 Core Back Plate

\section{Top Plate:}

It is used to clamp the top half of the mold with the moving half of the molding machine. The top plate is as shown in fig 6

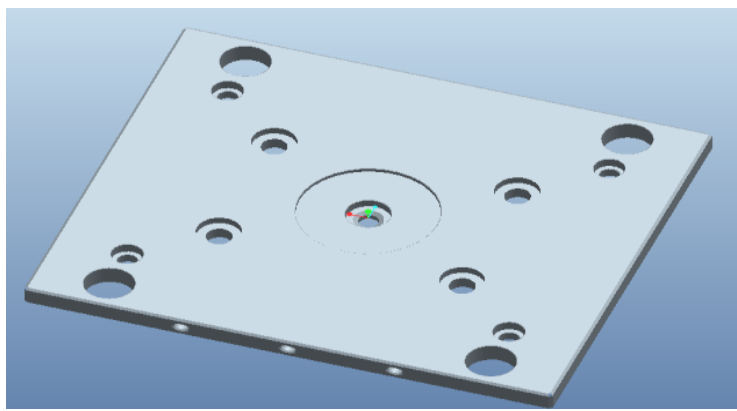

Fig 6 Top Plate

\section{Bottom Plate:}

It is used to clamp the bottom half of the mold with the fixed half of the molding machine.

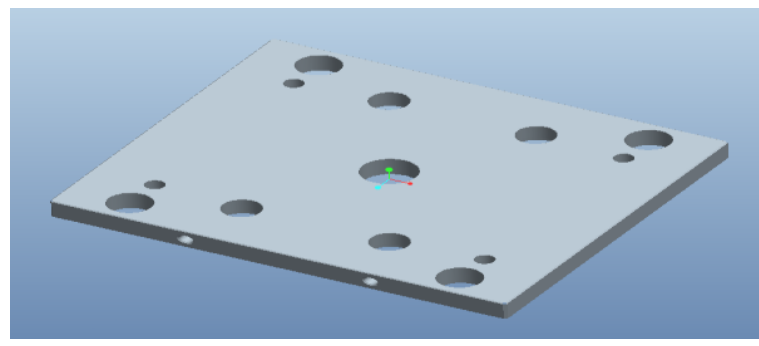

Fig 7 Bottom Plate 
IARJSET

\section{Ejector Plate:}

Ejector plate used to accommodate ejector pins.

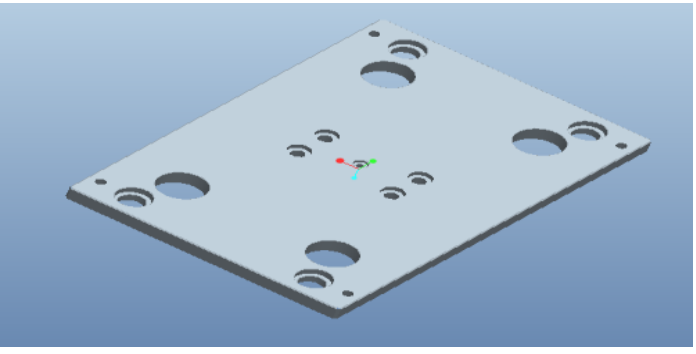

Fig 8 Ejector Plate

\section{Ejector Back Plate:}

Ejector back plate prevents the ejector pins coming out.

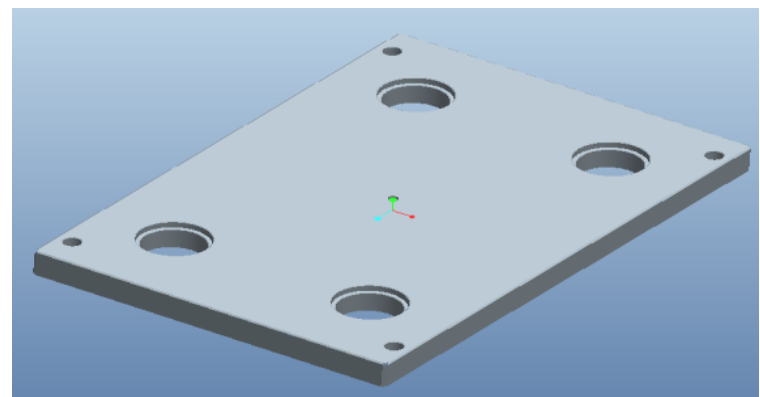

Fig 9 Ejector Back Plate

\section{Spacer Block:}

Mounted between the movable clamping plate (bottom plate) and the movable plate to give space and allow the ejector plate to move when ejecting the part.

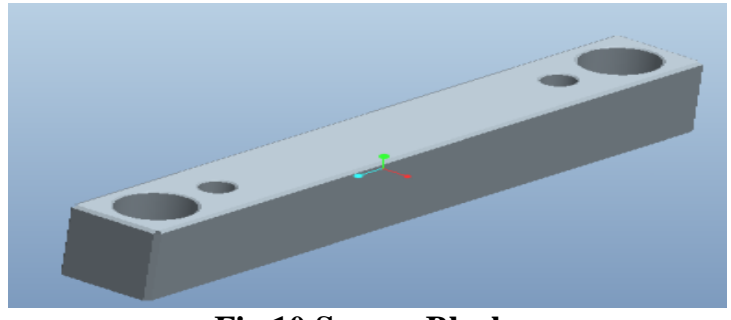

Fig 10 Spacer Block

\section{Guide Pillar and Guide Bush:}

The main purpose of a guide pillar and guide bush is to align fixed and moving halves of mold in each cycle. Guide Pillar and Guide Bush is as shown in fig 11
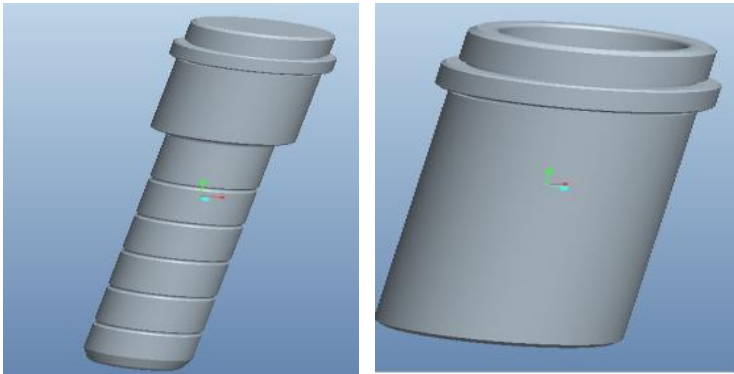

Fig 11 Guide Pillar and Guide Bush
Ejector guide Pillar and Guide Bush:

It ensures the alignment of ejector assembly therefore ejector pins will not get damaged. Ejector guide Pillar and Guide Bush is as shown in fig 12
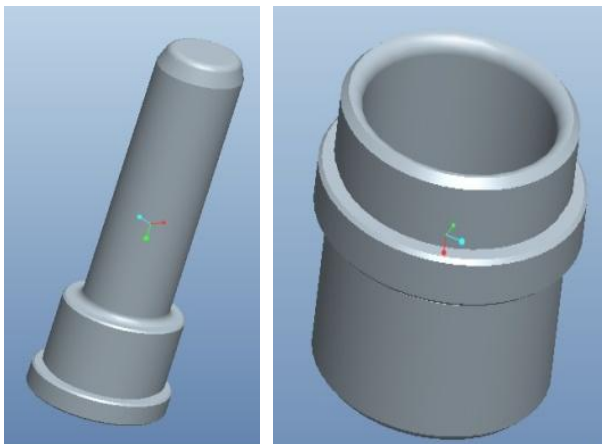

Fig 12 Ejector guide Pillar and Guide Bush

\section{Centering Bush and Register Ring:}

Centering bush Provides alignment between bottom plate and core back plate. Register Ring is used to align injection molding machine screw with injection mold.

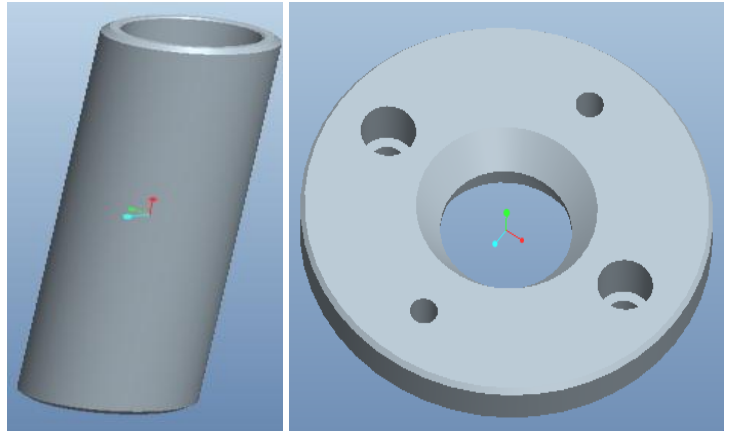

Fig 13 Centering Bush and Register Ring

\section{Sprue Bush and Retainer pin:}

The material enters into the mold through sprue bush. Retainer pin is used to hold the ejector

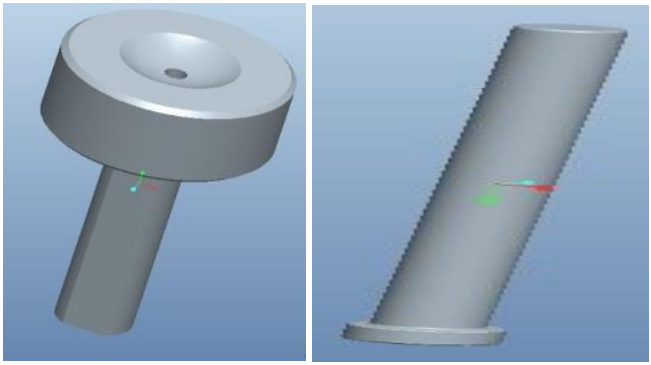

Fig 14 Sprue Bush and Retainer pin

\section{CONCLUSION}

The analysis will help the mold designer to design a perfect mold with minimum modifications and which will also reduce the time and cost. The Design of the Mold and the processing parameters has an influence over the quality of the component produced. hence while designing 


\section{IARJSET}

a mold, the designer needs to take many factors into account such as material, type of gate selection and position of gate, feed system details like gate size, sprue dimension $\&$ runner dimension and various defect such as warpage, sink mark, air traps and weld line.etc Thus mold flow software is a preventive and corrective tool, helps the engineer to analyze the process to decrease the cycle time and to improve the Quality of the Product.

\section{REFERENCES}

[1] Tuncay Erzurumlu, Babur Ozcelik "Minimization of warpage and sink index in injection-molded thermoplastic parts using Taguchi optimization method"Materials and Design vol 27, March 2005 pp 853-861

[2] Shunliang Jianga,b,Zhiguo Wanga,Goufa Zhoub,Weimin Yangc "An implicit control-volume finite element method and its time step strategies for injection molding simulation" Computers and Chemical Engineering vol 31, December 2006 pp 1407-1418

[3] "Hamdy Hassan, Nicolas Regnier, Guy Defaye " A 3D study on the effect of gate location on the cooling of polymer by injection molding" International Journal of Heat and Fluid Flow vol 30, June 2009 pp 1218-1229

[4] Wen-Chin Chen a, Gong-Loung Fub,c, Pei-Hao Taib, Wei-Jaw Deng d"Process parameter optimization for MIMO plastic injection molding via soft computing" Expert Systems with Applications vol 36, 2009 pp 1114-1122

[5] S.Rajalingam, Awang Bono and Jumat bin Sulaiman "A statistical experimental study on shrinkage of injection- molded part" International Journal of Humanities and Management Sciences (IJHMS) Volume 1, Issue 1, 2013 pp 2320-4044

[6] Dr.A. Riaz Ahamed, Dr.A.K. Shaik Dawood, R.Karthikeyan "Designing and optimizing the parameters which affect the molding process using Design of Experiment" International Journal of Research in Mechanical Engineering Volume 1, Issue 2, October

[7] S.Rajalingam, Awang Bono and Jumat bin Sulaiman "A statistical experimental study on shrinkage of injectionmolded part" International Journal of Humanities and Management Sciences (IJHMS) Volume 1, Issue 1, 2013 pp 2320-4044

\section{BIOGRAPHIES}

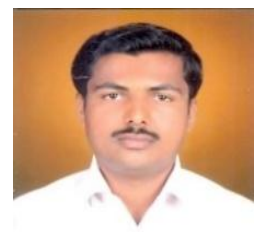

Pravin P. Shinde is currently working as Asst. Professor at dept. of Mechanical Engineering P.V.P.I.T. Budhgaon, Sangli. He has completed M.E. in Design Engineering from P.V.P.I.T. Budhgaon, Sangli (2015) and B.E. in Mechanical Engineering from A.I.T.R.C. Vita, Sangli(2013) and Diploma in Mechanical engineering from P.V.P.I.T. Budhgaon, Sangli (2010).

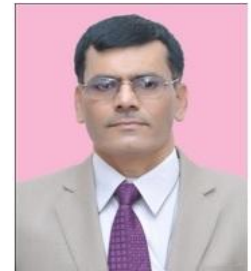

Suresh S Patil is currently working as Asso. Professor at dept. of Mechanical Engineering P.V.P.I.T. Budhgaon, Sangli, He has completed M.E. in Design Engineering from P.V.P.I.T. Budhgaon, Sangli (1996) and B.E.in Mechanical Engineering from Karnataka, University Dharwad (1984). He has member of "Tribology society of India". He has teaching experience for both UG and PG programs.

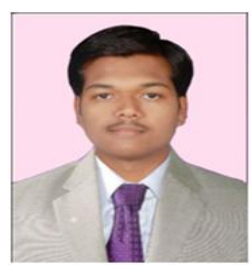

Sandesh S Awati is currently working as Asst. Professor at dept.of Mechanical Engineering P.V.P.I.T. Budhgaon, Sangli. He has completed M.E. in Design Engineering from P.V.P.I.T. Budhgaon, Sangli and B.E. in Mechanical Engineering from PVPIT Budhgaon, Sangli(2013).

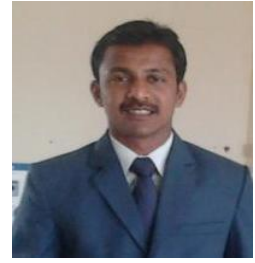

Rahul P Suryavanshi is currently working as Asst. Professor at dept. of Mechanical Engineering D.A.C.O.E Karad. He has Pursing M.E. in Design Engineering from PVPIT Budhgaon and completed B.E. in Mechanical Engineering from PVPIT Budhgaon 